\title{
The Novel Biomarker of Germ Cell Tumours, Micro-RNA-371a-3p, Has a Very Rapid Decay in Patients with Clinical Stage 1
}

\author{
Arlo Radtke $^{a}$ Finja Hennig ${ }^{a}$ Raphael lkogho ${ }^{b}$ Johannes Hammel ${ }^{c}$ \\ Petra Anheuser $^{b, d}$ Christian Wülfing ${ }^{e}$ Gazanfer Belge ${ }^{a}$ \\ Klaus-Peter Dieckmann ${ }^{\text {b, e }}$ \\ ${ }^{a}$ Faculty of Biology and Chemistry, University of Bremen, Bremen, Germany; ${ }^{b}$ Department of Urology, Albertinen \\ Krankenhaus, Hamburg, Germany; ${ }^{\mathrm{C}}$ Department of Urology, Klinikum Bremen-Mitte, Bremen, Germany; ${ }^{\mathrm{d}}$ Department \\ of Urology, Asklepios Klinik St. Georg, Hamburg, Germany; ${ }^{e}$ Department of Urology, Hodentumorzentrum Hamburg, \\ Asklepios Klinik Altona, Hamburg, Germany
}

\section{Keywords}

Germ cell tumour · Seminoma - Nonseminoma ·

MicroRNA-371a-3p $\cdot$ Serum biomarker

\begin{abstract}
Background: Accumulating evidence suggests serum levels of microRNA (miR)-371a-3p to be a novel tumour marker of testicular germ cell tumours (GCTs). Presently, there is only limited information regarding the velocity of decline of serum levels in response to treatment. Patients and Methods: Twenty-four patients with testicular GCT (20 seminoma, 4 nonseminoma, median age 40 years) with clinical stage 1 had measurements of serum levels of miR-371a-3p preoperatively and repeatedly on the following 3 days. Three had additional tests done within $24 \mathrm{~h}$ after surgery. Measurement results were analysed using descriptive statistical methods. Results: Serum levels dropped to $2.62,1.27$, and $0.47 \%$ of the preoperative level within 1,2 , and 3 days, respectively. The computed half-life amounts to $3.7-7 \mathrm{~h}$. The
\end{abstract}

() 2018 S. Karger AG, Basel

E-Mail karger@karger.com

www.karger.com/uin velocity of decay is significantly associated with tumour size. Conclusions: Serum-levels of miR-371a-3p have a short halflife of less than $12 \mathrm{~h}$. The rapid decay after treatment represents a valuable feature confirming the usefulness of miR$371 a-3 p$ as a valuable serum biomarker of GCT.

(c) 2018 S. Karger AG, Basel

\section{Introduction}

The clinical management of testicular germ cell tumours (GCTs) largely relies on the monitoring of the serum tumour markers alpha fetoprotein (AFP), beta human chorionic gonadotropin and lactate dehydrogenase [1]. However, clinical decision-making is often hampered by the fact that only $50-60 \%$ of GCTs express one of these markers [2-4]. In the cases with absent marker expression radiological methods, for example, computed tomography is employed for monitoring the treatment. Recently, serum levels of microRNAs (miRs) of the clusters 
miR-371-3 and miR-302/367 have been suggested as novel biomarkers of GCT [5-9]. Among the candidate miRs, miR-371a-3p proved to be the most promising marker with a sensitivity of $88.7-90 \%$ and a specificity of $86-$ 93.4\% [10-13]. However, before the implementation of this marker in clinical practice, validation of its usefulness in a larger international patient cohort is required [14, 15]. Also, for employing miR-371a-3p serum levels as a tool for clinical decision making, information about the velocity of decay of this substance in serum is required. According to the well-defined prerequisites of a useful tumour marker outlined by Lange and Winfield [16], the marker substance should be cleared quite rapidly from serum after removing the source of marker production. If the decay of a candidate substance would take longer than 1 week, that substance would probably not qualify as a useful tumour marker because changes of the disease status would be mirrored with undue delay [17]. Regarding miR-371a-3p, preliminary data suggests a very rapid halflife $[18,19]$. However, that information is based only on very few patients and no further information is available to date. We therefore evaluated the decay of serum levels of miR-371a-3p in an extended patient sample. We also looked to any associations of the decay kinetics with histology of the GCT and with other factors. The goal of our study was to further qualify serum levels of miR-371a-3p as useful tumour markers of GCT.

\section{Methods}

\section{Patients and Samples}

Twenty-four patients with GCT confined to the testis (i.e., clinical stage [CS]1) were enrolled for the present study - 20 with pure seminoma and 4 with nonseminomatous tumours. The median age was 40 years (interquartile range [IQR] 17.25 years). In all patients, the size of the primary tumour was registered for correlation with serum miR levels. The median tumour size was $31.5 \mathrm{~mm}$ (IQR 15$47 \mathrm{~mm}$ ). All of the patients underwent repeated blood aspirations for the measurement of serum levels of miR-371a-3p at consecutive time-points after surgery. All had preoperative examinations, as well as blood aspirations on the first and second day after surgery. On the third day after orchiectomy, only 18 patients were available. Of the 24 patients, 3 underwent multiple tests during the first $24 \mathrm{~h}$ after surgery, 1 patient (\#22, online suppl. Table 1; for all online suppl. material, see www.karger.com/doi/10.1159/000488771) had additional serum samples taken at 4 and $8 \mathrm{~h}$, respectively, after surgery, and 2 others (\#23 and \#24, online suppl. Table 1) had each one additional sample taken at 10 and $4 \mathrm{~h}$ respectively. Twenty male patients with non-malignant testicular disease were recruited as controls (online suppl. Table 2). The median age of these patients was 33 years (IQR 22-48 years). All participants gave their informed consent. The study received ethical approval (Ärztekammer Bremen, reference 301, 2011).

\section{Laboratory Methods}

Serum levels of miR-371a-3p were measured by quantitative PCR as reported earlier $[10,20]$. The total RNA was isolated from $200 \mu \mathrm{L}$ of cubital vein serum using the miRNeasy mini kit (Qiagen, Hilden, Germany) according to the manufacturer's instructions. Reverse transcription was conducted with the TaqMan MicroRNA Reverse Transcription Kit (Thermo Fisher Scientific, Schwerte, Germany) and stem-loop primers for miR-371a-3p (assay ID 002124) and the endogenous control miR-30b-5p (assay ID 000602). The cDNA was preamplified by a standard PCR and quantified in a qPCR using the aforementioned TaqMan assays and a 7500 Fast Real Time PCR System (Thermo Fisher Scientific, Schwerte, Germany). The relative quantity (RQ) of miR-371a-3p was calculated using the $\Delta \Delta \mathrm{C}_{\mathrm{T}}$ method [21].

\section{Statistical Analysis}

The miR-371a-3p expression of the various subgroups is presented as median with IQRs. The difference between independent samples (tumour patients and controls) was analysed with the Mann-Whitney U test. Differences between dependent samples (expression at different time points in the same patient cohort) were assessed with the Wilcoxon ranked sign test. The miR-371a$3 p$ half-life was estimated by the calculation of the linear equation of a straight line between the 2 data points surrounding the $y$-value of $50 \% \mathrm{miR}-371 \mathrm{a}-3 \mathrm{p}$ expression by employing the measurement results of the 3 patients with additional blood aspirations within the first $24 \mathrm{~h}$ after orchiectomy. The Pearson correlation was used for correlation analysis of interval scaled data. Significant differences were assumed at $p<0.05$.

\section{Results}

Within $24 \mathrm{~h}$ after orchiectomy, the serum miR-371a$3 p$ levels dropped to $2.62 \%$ of the preoperative level to decline further to $1.27 \%$ after $48 \mathrm{~h}$ and to $0.47 \%$ after $72 \mathrm{~h}$ (Fig.1a). The differences between the median RQ values measured preoperatively and the median miRNA expressions at 24,48 , or $72 \mathrm{~h}$ after orchiectomy, respectively, were statistically significant $(p<0.001$ for all comparisons), as were the differences between the median levels measured after $24 \mathrm{~h}$ and after $48 \mathrm{~h}$, as well as the difference between the RQ values after 24 and $72 \mathrm{~h}(p=0.001$ and $p<0.001$, respectively). The difference between the levels at $48 \mathrm{~h}$ and 72 was no longer significant, but the median levels of preoperative tumour samples, as well as those at 24, 48 and $72 \mathrm{~h}$, were significantly different from the median level of controls $(p<0.001, p<0.001, p=$ 0.009 , and $p=0.043$, respectively). There was no statistically significant difference between the miR-371a-3p expression in seminoma and non-seminoma at the different time points (online suppl. Fig. 1).

In the first patient who had done multiple tests during the first day after surgery (\#22; Fig. 1b), the miR-371a-3p
2
Urol Int

DOI: $10.1159 / 000488771$
Radtke/Hennig/Ikogho/Hammel/ Anheuser/Wülfing/Belge/Dieckmann 


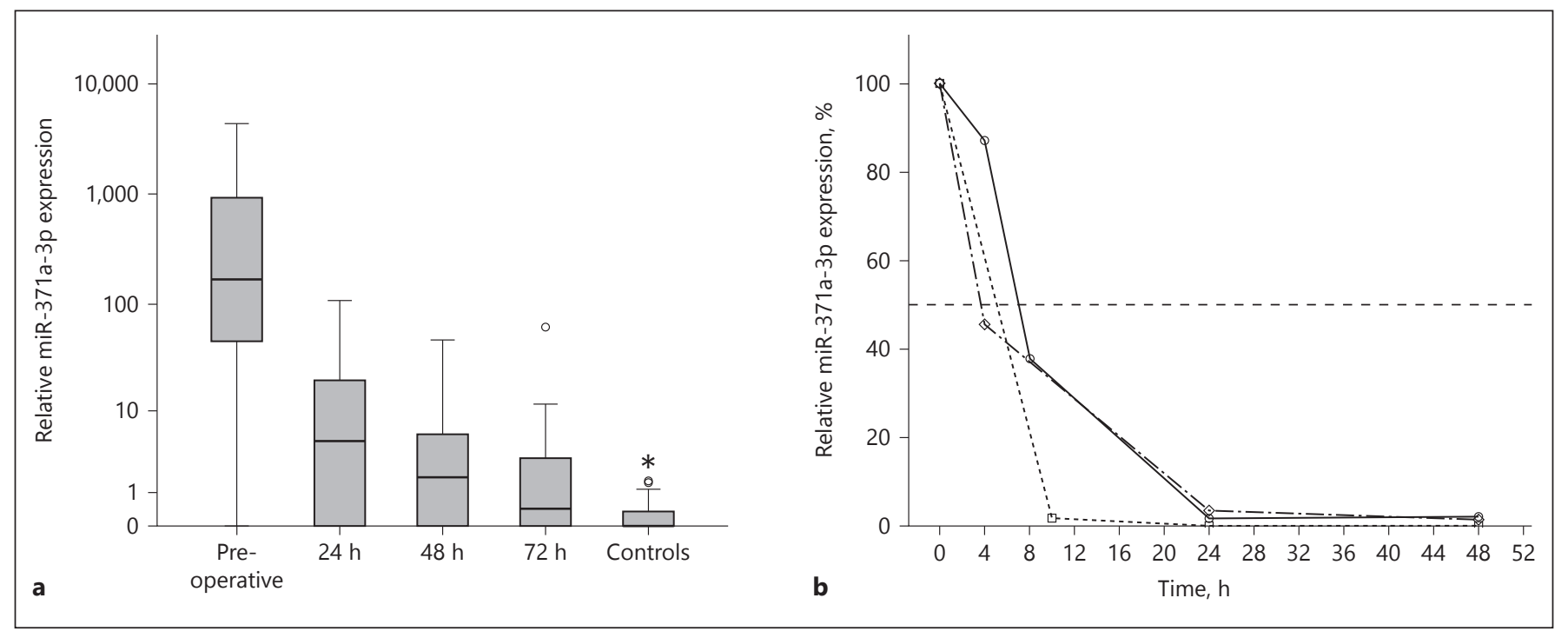

Fig. 1. a Box plot showing the different relative microRNA (miR)371a-3p expressions in serum samples of patients with testicular germ cell tumours (GCTs) at consecutive time points following orchiectomy. See the Methods section for clinical details. Horizontal line within box denotes median serum relative quantity (RQ) value, upper and lower limits of boxes denote inter quartile ranges (IQRs). Whiskers show lowest and highest values within a range of

expression declined to $87.05 \%$ after $4 \mathrm{~h}$ and to $37.82 \%$ after $8 \mathrm{~h}$, arriving at $1.62 \%$ after $24 \mathrm{~h}$ and $2.1 \%$ after $48 \mathrm{~h}$. The second patient (\#23) dropped to $1.8 \%$ of the pre-operative value after $10 \mathrm{~h}$, to reach undetectable levels of miR-371a-3p after 24 and $48 \mathrm{~h}$. MiR-371a-3p values of the third patient (\#24) dropped to $45.52 \%$ after $4 \mathrm{~h}$, to further decrease to $3.38 \%$ after $24 \mathrm{~h}$ and to $1.38 \%$ after $48 \mathrm{~h}$. The computed halflife values of miR-371a-3p serum levels amount to $7.01 \mathrm{~h}$

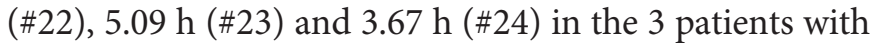
multiple blood aspirations within the first $24 \mathrm{~h}$ after surgery.

We observed a significant correlation of preoperative RQ-values with tumour size ( $p=0.001, r^{2}=0.38$; Fig. 2$)$, with larger tumours featuring higher expressions than smaller ones.

To further assess the velocity of miRNA decay, a cutoff of RQ $=1.933$ representing the upper level of norm (ULN) of miR serum levels was calculated by employing the preoperative miR expressions of the 24 GCT patients and 20 controls in a receiver operating characteristics analysis (online suppl. Fig. 2). The time needed for the value to fall below that cutoff value was used as an estimate for the velocity of miRNA decay. Sixteen of the 24 patients dropped below the cutoff value within $72 \mathrm{~h}$ (Fig. 3). There was a significant correlation between tumour size and the velocity of decay, with larger tumours

Novel Biomarker of GCTs, miR-371a-3p,

Has a Rapid Decay in Patients with CS1
1.5 IQR. The y-axis represents a logarithmic scale. b Line graph showing the rapid decay of serum miR-371a-3p levels in 3 patients with multiple tests during the first $24 \mathrm{~h}$ after surgery. See the Methods section for clinical details. The y-axis represents percentages of the preoperative serum values. The horizontal dashed line depicts the $50 \%$ reduction level.

needing more time to drop below the cutoff value ( $p=$ $\left.0.016, r^{2}=0.348\right)$. No significant difference was observed between the velocities of decay of seminomas and nonseminomas respectively. Likewise, patients' age was not correlated with the velocity of decay.

\section{Discussion}

The crucial result of the present study is the very short half-life of miR-371a-3p serum levels of 3.67-7.01 h. This result is in line with preliminary findings $[18,19]$. As outlined in classical reviews regarding the role of tumour markers, serum levels should mirror the activity of the disease allowing clinical decisions to be made in relation to the serum levels actually measured [16]. Thus, a rapid decay after treatment is quite a favourable feature of a tumour marker because any changes in the extent of disease will be immediately highlighted by the marker [22]. Among the markers currently in use, beta human chorionic gonadotropin also has a short half-life with about $36 \mathrm{~h}$ [23]. AFP involves a considerably longer half-life of 5-7 days [24-26]. Particularly in CS1 patients with elevated AFP levels, it is sometimes inconvenient to wait for appropriate marker decline to be sure about the stage 1 


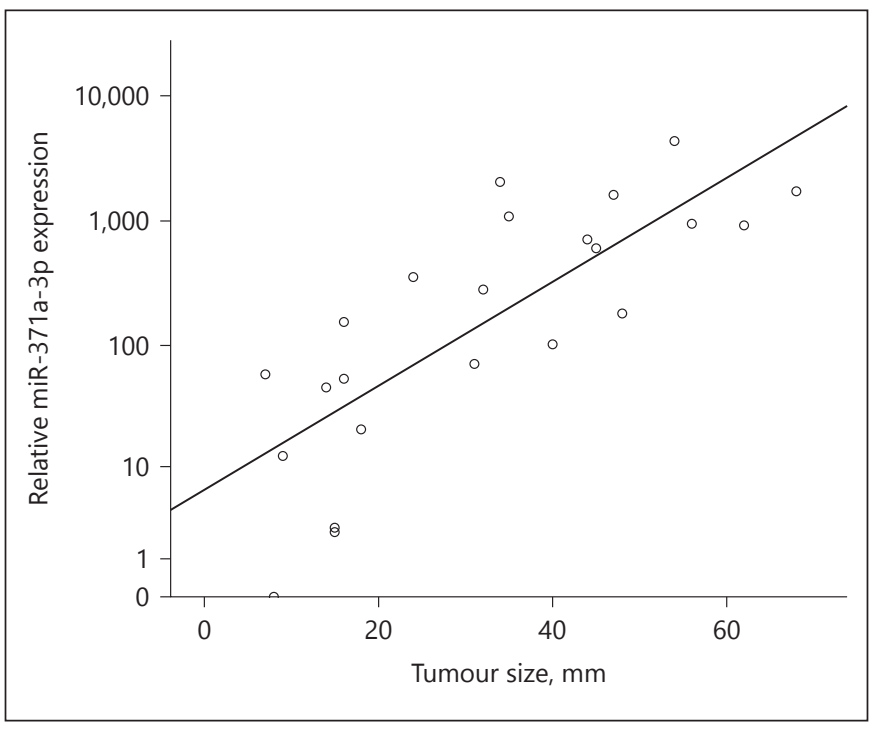

Fig. 2. Scatter plot showing the correlation between the preoperative relative expression of $\mathrm{miR}-371 \mathrm{a}-3 \mathrm{p}$ and the tumour size in 24 patients with testicular germ cell tumour (GCT). The y-axis is displayed in a logarithmic scale.

condition [27]. A half-life of less than $24 \mathrm{~h}$, as found for miR-371a-3p, thus represents a highly useful feature of a serum tumour marker [15].

Clinically important is the association of the velocity of decay with the size of the primary tumour and with the initial extent of marker elevation [28]. Thus, patients with larger tumours and with higher miR levels have a somewhat delayed decline although the decay is still faster than that of the classical markers. Probably, the association of marker decay with tumour bulk will not considerably impact the clinical utility of the test.

No associations of the marker decay have been observed with patient age and this finding is the same with the classical markers [29]. Also, no association of miR decay was found with histology of the primary. However, this finding might be premature because it rests on only 4 patients with nonseminoma, and particularly nonseminoma may involve a number of various histologies including teratoma. To obtain safe information about the velocity of decay of miR levels in nonseminoma a larger patient sample needs to be evaluated.

Although there is now clear evidence regarding the very rapid decline of miR levels in CS1 patients, there is still limited information about the velocity of decay in metastasized cases in response to therapy. Principally, the regression of tumour marker levels in metastasized cases

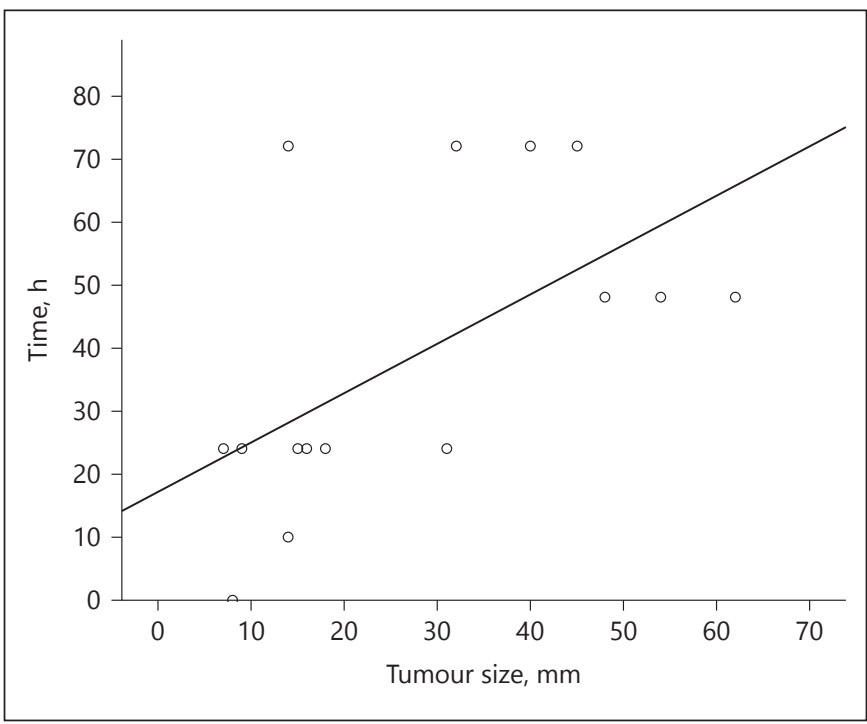

Fig. 3. Scatter plot showing the velocity of miR-371a-3p decay in relation to the tumour size. $\mathrm{X}$-axis denotes tumour-size $(\mathrm{mm})$; $\mathrm{y}$ axis denotes the time needed to reach the cut-off level. Only those patients whose miRNA levels dropped below the cutoff value within $72 \mathrm{~h}(n=16)$ are included. The figure clearly illustrates that smaller tumours arrive more rapidly at the cutoff level.

may be different from CS1 cases depending on tumour bulk and on the response to therapy [24, 30]. In a previous report, we found the majority of CS2-3 patients to reach normalization of miR levels already after the first cycle of chemotherapy upon repeat measurements during treatment [10]. This would signify a very rapid decline in metastasized cases too. As a matter of fact, a similarly rapid decline should be expected from a biological point of view, likewise, because the biological clearance mechanisms of microRNAs are most probably identical in all patients with GCT. Clearly, this understanding requires confirmation in a larger prospective series.

Limitations of the present study involve the low number of patients analysed. Further, the conclusions are limited by the very low number of patients with nonseminoma, particularly in light of the histologic variability of nonseminomatous GCTs. An overall appraisal of the decay of miR-371a-3p is limited by the lack of metastasized cases in the present series. Also, the half-life was computed from only 3 patients with varying time points of examination; therefore, these values should be considered with care. In light of the obviously very rapid decline of miR levels, more measurements within the first $24 \mathrm{~h}$ after orchiectomy would have been desirable to compute a more accurate decay curve. However, such data are hard to accomplish because multiple blood aspirations within 
1 day are rather inconvenient for patients and represent ethical problems on the one side and create logistic-practical problems on the other side.

\section{Conclusion}

The very rapid decay of miR-371a-3p serum levels after removal of the source of this substance with a half-life of less than $12 \mathrm{~h}$ is a highly favourable feature and adds further support to the value of this $\mathrm{miR}$ as a serum biomarker of GCTs.

\section{Acknowledgements}

The authors gratefully acknowledge the technical assistance provided by the Laboratory Staffs of Albertinen-Krankenhaus Hamburg, Klinikum Bremen-Mitte and Asklepios Klinik Altona, Hamburg.

\section{Disclosure Statement}

G.B. and K.-P.D. each possess $10 \%$ ownership shares of miRdetect, $\mathrm{GmbH}$, Bremen, a company aiming to develop a commercially available test for measuring microRNAs in serum. MiRdetect holds a patent for the measurement of miRNA in body fluids at the limit of detection. A further patent for the use of miR-371a-3p as a marker for GCNis was filed by miRdetect/University of Bremen on November 2nd, 2016.

None of the other authors declare any conflict of interests with publishing this report.

\section{Funding Sources}

The present study received support from Wilhelm Sander Stiftung, München (No., 2014.178.2), and Albertinen-Stiftung, Hamburg $(1-3,2016)$. The sponsors had no role in study design; in the collection, analysis and interpretation of data; in the writing of the report; and in the decision to submit the article for publication.

\section{References}

$\checkmark 1$ Albers P, Albrecht W, Algaba F, Bokemeyer C, Cohn-Cedermark G, Fizazi K, Horwich A, Laguna MP, Nicolai N, Oldenburg J: Guidelines on testicular cancer: 2015 update. Eur Urol 2015;68:1054-1068.

$\checkmark 2$ Murray MJ, Huddart RA, Coleman N: The present and future of serum diagnostic tests for testicular germ cell tumours. Nat Rev Urol 2016;13:715-725.

3 Neumann A, Keller T, Jocham D, Doehn C: [Human placental alkaline phosphatase (hPLAP) is the most frequently elevated serum marker in testicular cancer]. Aktuelle Urol 2011;42:311-315.

-4 Molina Saera J, Aparicio Urtasun J, Díaz Beveridge R, Palomar Abad L, Giménez Ortiz A, Ponce Lorenzo J, Montalar Salcedo J: Epidemiological pattern and time trends in testicular germ-cell tumors: a single institution 20year experience. Clin Transl Oncol 2006;8: 588-593.

5 Murray MJ, Coleman N: Testicular cancer: a new generation of biomarkers for malignant germ cell tumours. Nat Rev Urol 2012;9:298_300.

6 6 Bezan A, Gerger A, Pichler M: Micrornas in testicular cancer: implications for pathogenesis, diagnosis, prognosis and therapy. Anticancer Res 2014;34:2709-2713.

-7 Belge G, Dieckmann KP, Spiekermann M, Balks T, Bullerdiek J: Serum levels of microRNAs miR-371-3: a novel class of serum biomarkers for testicular germ cell tumors? Eur Urol 2012;61:1068-1069.

8 Dieckmann KP, Spiekermann M, Balks T, Ikogho R, Anheuser P, Wosniok W, Loening T,
Bullerdiek J, Belge G: MicroRNA miR-371a$3 p-a$ novel serum biomarker of testicular germ cell tumors: evidence for specificity from measurements in testicular vein blood and in neoplastic hydrocele fluid. Urol int 2016;97:76-83.

-9 Gillis AJ, Rijlaarsdam MA, Eini R, Dorssers LC, Biermann K, Murray MJ, Nicholson JC, Coleman N, Dieckmann KP, Belge G, Bullerdiek J, Xu T, Bernard N, Looijenga LH: Targeted serum mirna (TSmiR) test for diagnosis and follow-up of (testicular) germ cell cancer patients: a proof of principle. Mol Oncol 2013; 7:1083-1092.

10 Dieckmann KP, Radtke A, Spiekermann M, Balks T, Matthies C, Becker P, Ruf C, Oing C, Oechsle K, Bokemeyer C, Hammel J, Melchior S, Wosniok W, Belge G: Serum levels of MicroRNA miR-371a-3p: a sensitive and specific new biomarker for germ cell tumors. Eur Urol 2017;71:213-220.

-11 van Agthoven T, Looijenga LHJ: Accurate primary germ cell cancer diagnosis using serum based microrna detection (amptsmir test). Oncotarget 2017;8:58037-58049.

12 Syring I, Bartels J, Holdenrieder S, Kristiansen G, Müller SC, Ellinger J: Circulating serum miRNA (miR-367-3p, miR-371a-3p, miR-372-3p and miR-373-3p) as biomarkers in patients with testicular germ cell cancers. J Urol 2015;193:331-337

13 Murray MJ, Bell E, Raby KL, Rijlaarsdam MA, Gillis AJ, Looijenga LH, Brown $\mathrm{H}$, Destenaves B, Nicholson JC, Coleman N: A pipeline to quantify serum and cerebrospinal fluid micrornas for diagnosis and detec- tion of relapse in paediatric malignant germ-cell tumours. Br J Cancer 2016;114: 151-162.

14 Costa AL, Lobo J, Jerónimo C, Henrique R: The epigenetics of testicular germ cell tumors: Looking for novel disease biomarkers. Epigenomics 2017;9:155-169.

15 Ellinger J, Müller SC, Dietrich D: Epigenetic biomarkers in the blood of patients with urological malignancies. Expert Rev Mol Diagn 2015;15:505-516.

16 Lange PH, Winfield HN: Biological markers in urologic cancer. Cancer 1987;60(suppl 3): 464-472.

17 Bidart JM, Thuillier F, Augereau C, Chalas J, Daver A, Jacob N, Labrousse F, Voitot H: Kinetics of serum tumor marker concentrations and usefulness in clinical monitoring. Clin Chem 1999;45:1695-1707.

18 Spiekermann M, Belge G, Winter N, Ikogho R, Balks T, Bullerdiek J, Dieckmann KP: MicroRNA miR-371a-3p in serum of patients with germ cell tumours: evaluations for establishing a serum biomarker. Andrology 2015; 3:78-84.

19 van Agthoven T, Eijkenboom WMH, Looijenga LHJ: MicroRNA-371a-3p as informative biomarker for the follow-up of testicular germ cell cancer patients. Cell Oncol (Dordr) 2017;40:379-388.

20 Radtke A, Cremers JF, Kliesch S, Riek S, Junker K, Mohamed SA, Anheuser P, Belge G, Dieckmann KP: Can germ cell neoplasia in situ be diagnosed by measuring serum levels of microRNA371a-3p? J Cancer Res Clin Oncol 2017;143:2383-2392.
Novel Biomarker of GCTs, miR-371a-3p, Has a Rapid Decay in Patients with CS1 
-21 Livak KJ, Schmittgen TD: Analysis of relative gene expression data using real-time quantitative PCR and the 2(-Delta Delta C(T)) method. Methods 2001;25:402-408.

22 Bates SE: Clinical applications of serum tumor markers. Ann Int Med 1991;115:623638.

23 Gilligan TD, Seidenfeld J, Basch EM, Einhorn LH, Fancher T, Smith DC, Stephenson AJ, Vaughn DJ, Cosby R, Hayes DF: American society of clinical oncology clinical practice guideline on uses of serum tumor markers in adult males with germ cell tumors. J Clin Oncol 2010;28:33883404.
24 See WA, Cohen MB, Hoxie LD: Alpha-fetoprotein half-life as a predictor of residual testicular tumor. Effect of the analytic strategy on test sensitivity and specificity. Cancer 1993;71:2048-2054.

25 Krege S, Albers P, Heidenreich A: Markersysteme beim Hodentumor. Urologe A 2011;50: 313-321.

26 Ehrlich Y, Beck SD, Foster RS, Bihrle R, Einhorn LH: Serum tumor markers in testicular cancer. Urol Oncol 2013;31:17-23.

27 Dieckmann KP, Anheuser P, Simonsen H, Höflmayer D: Pure testicular seminoma with non-pathologic elevation of alpha fetoprotein: a case series. Urol Int 2017;99:353-357.
28 Anheuser P, Radtke A, Wülfing C, Kranz J, Belge G, Dieckmann KP: Serum levels of microRNA371a-3p: A highly sensitive tool for diagnosing and staging testicular germ cell tumours: a clinical case series. Urol Int 2017;99:98-103.

29 Doherty AP, Bower M, Christmas TJ: The role of tumour markers in the diagnosis and treatment of testicular germ cell cancers. Br J Urol 1997;79:247-252.

30 Massard C, Kramar A, Beyer J, Hartmann JT, Lorch A, Pico JL, Rosti G, Droz JP, Fizazi K: Tumor marker kinetics predict outcome in patients with relapsed disseminated nonseminomatous germ-cell tumors. Ann Oncol 2013;24:322-328. 